\title{
Research on the Influence of Perceived Value of Social Reading on Teenagers' Reading Ability
}

\author{
Jie Ma', Wei Gong2* \\ 1School of Educational Science and Technology, Guangdong Polytechnic Normal University, Guangzhou 510665, \\ Guangdong Province, China \\ ${ }^{2}$ Guangzhou Univ Chinese Med, Guangzhou 510006, Guangdong Province, China \\ *Corresponding author: Wei Gong, gongwei@gzucm.edu.cn

\begin{abstract}
Adolescence is the golden stage for developing reading ability. Reading ability is an important factor in promoting teenagers' know-how and cognitive structure. For teenagers who are at the stage of forming views on the world, life, and values, reading is a key part of understanding the external world. This study is an empirical analysis conducted on 210 teenagers through questionnaires to explore the influence of perceived value of social reading on teenagers' reading ability by using the structural equation model. The results show that first, the perceived value of social reading affects teenagers' reading ability; second, social reading motivation is the mediator of the above relationship; third, the perceived value of social reading affects teenagers' reading ability through reading motivation. In regard to that, it is proposed that the characteristics of perceived value should be made use to stimulate students' learning motivation and improve teenagers' reading ability in the process of policy formulation of governmental departments and the teaching in schools.
\end{abstract}

Keywords: Social reading; Perceived value; Reading motivation; Reading ability; Teenagers

Publication date: October 2021; Online publication: October 29, 2021

\section{Introduction}

Adolescence is the golden stage for developing reading skills. Reading ability is a pivotal factor in promoting teenagers' know-how and cognitive structure. For teenagers who are at the stage of forming views on the world, life, and values, reading is a key part of understanding the external world. With the rapid development of network technology, social reading, as a new mode of digital reading centered on readers and linked by social relations, has been integrated into the life of adolescents. Moreover, its sharing and social characteristics have been highly praised by them. The results of the 11th National Reading Survey have shown that the rate of digital reading is $50.1 \%$, among which $44.4 \%$ of readers read online through the internet and $41.9 \%$ read through their cell phones ${ }^{[1]}$. Perceived value is a measurement that evaluates the value of things from many aspects, serving as a preference and evaluation of target objects. The perceived value under social reading is accompanied by the popularity of social reading, where more reading platforms and reading resources are emerging. Teenagers can evaluate a variety of reading resources in an all-round way as well as choose their own reading platforms and reading materials. However, the lack of social experience and the immature ability of value selection make it necessary to discuss whether the value perception of adolescents on social reading can promote their reading ability.

Perceived value in the context of social reading is the result of a reader's assessment on the utility of a product in the process of social reading. Some scholars have studied the perceived value. Li Wu divided the perceived value into social value, price value, content value, interactive value, and interface design value. The researcher studied and analyzed the influence of perceived value on users' satisfaction ${ }^{[2]}$. Xuan 
Haiyan and other researchers studied the influence of app marketing on the purchasing behavior of young people from the perspective of perceived value ${ }^{[3]}$. In another study, Zheng Jiuliang used perceived value as an independent variable to study the role of perceived quality and perceived value of online popular science channels on users' satisfaction ${ }^{[4]}$. From the aforementioned studies, it can be seen that perceived value, as an all-round value judgement of usage experience, is widely used in various fields of research. Reading motivation in the context of social reading is a direct motivation for teenagers' reading behavior. Reading motivation is the process of an individual's self-concept and the recognition of the value of reading. The ability to stimulate adolescents' reading interest is an important part of the school teaching process. Numerous empirical studies have also shown that there is a significant effect between reading motivation and reading ability. Gu Honglei used reading motivation as an intermediary to study the role of family socioeconomic status on primary school students' independent reading ${ }^{[5]}$. Liu Haitao argued that reading interest, reading ability, and reading motivation can arouse reading behavior through certain stimulation. It can be seen that reading motivation needs to be perceived and mobilized, and only by perceiving the value of reading resources can reading motivation be fully mobilized, thus promoting the reading ability of teenagers.

In recent years, whether social reading can promote reading ability has received extensive academic attention. Liu Xiaoli discussed the relationship between the perceived value and users' willingness. The scholar conducted an empirical study on social reading platforms ${ }^{[6]}$. Li Jincheng studied the relationship between reading motivation and reading ability as well as conducted an empirical study on the impact of multiple reading motivations on teenagers' reading ability ${ }^{[7]}$. An empirical study has been conducted to explore the impact of perceived value of social reading for the mediating role of reading motivation on the improvement of adolescents' reading ability in this paper.

\section{Research method}

\subsection{Sample selection and date collection}

According to the essence of the research, this study adopted the questionnaire survey method to obtain relevant data. The research mainly adopted a combination of an online survey and a paper survey, with a total of 287 questionnaires collected, of which 239 were valid questionnaires. Considering the representativeness of the study, this study randomly selected teenagers of different age groups (14-35 years old) as the main research group, with a total of 226 teenagers. As shown in Table 1, among them, there were 97 teenagers with age 14-17, 103 teenagers with age 18-24, and 10 teenagers over 25 years old.

Table 1. Statistical characteristics of subjects

\begin{tabular}{|c|c|c|c|c|c|c|c|c|}
\hline & \multicolumn{2}{|c|}{ Gender } & \multicolumn{6}{|c|}{ Education level } \\
\hline & Male & Female & Graduate & Undergraduate & $\begin{array}{c}\text { Junior college } \\
\text { and vocational } \\
\text { college }\end{array}$ & $\begin{array}{l}\text { Senior high } \\
\text { school }\end{array}$ & $\begin{array}{c}\text { Vocational } \\
\text { high } \\
\text { school } \\
\end{array}$ & $\begin{array}{c}\text { Junior } \\
\text { high } \\
\text { school }\end{array}$ \\
\hline Frequency & 85 & 125 & 17 & 63 & 2 & 50 & 42 & 36 \\
\hline percentage & 40.5 & 59.5 & 0.08 & 0.3 & 0.01 & 0.24 & 0.2 & 0.17 \\
\hline
\end{tabular}

\subsection{Research tool and process}

Because of the important influence of social reading motivation on perceived value and reading ability, this study first constructed a scale of the influence of perceived value of social reading on reading ability based on previous literature research results and analyzed the data using Statistical Package for the Social 
Sciences (SPSS) 21.0 and Amos $21.0^{[8,9]}$. The scale contained three variables. First, the independent variable is the perceived value of social reading. Second, the intermediary variable is the social reading motivation. The third variable is the teenagers' reading ability. This study took into consideration of previous studies to determine the basic dimensions of the questionnaire. The perceived value of social reading adopted three dimensions: functional value, emotional value, and social value, in the questionnaire by Liu Xiaoli and other researchers ${ }^{[6]}$. Social reading motivation adopted five dimensions of reading motivation; namely, social interaction, personal development, other people's identity, information acquisition, and emotional expression, as well as two dimensions of reading comprehension ability and network information evaluation ability. The questionnaire consisted of 34 questions with the Likert 5-point scale mainly used: 1 indicating "very inconsistent" while 5 indicating "very consistent." The higher the total score is, the stronger the perceived value, reading motivation, or reading ability will be.

\subsection{Research hypothesis}

To study the effects of perceived value of social reading and reading motivation on teenagers' reading ability, and their interrelationships. It is necessary to discuss not only the direct effect of perceived value of social reading on teenager' reading ability, but also whether there is a mediating effect of reading motivation in it, based on which, the study proposes a few hypotheses.

H1: The perceived value of social reading has a significant impact on teenagers' reading ability, and the path is "perceived value of social reading $\rightarrow$ teenagers' reading ability."

$\mathrm{H} 2$ : Reading motivation has a significant impact on teenagers' reading ability, and the path is "reading motivation $\rightarrow$ teenagers' reading ability."

H3: Reading motivation plays an intermediary role in the influence of perceived value of social reading on teenagers' reading ability; that is, the perceived value of social reading affects teenagers' reading ability by influencing reading motivation, and the path is "perceived value of social reading $\rightarrow$ reading motivation $\rightarrow$ teenagers' reading ability."

\subsection{Research process}

First, item analysis and exploratory factor analysis of the scales were conducted, and the results showed that the homogeneous error of the data in this study was within a reasonable range. The overall reliability of the scale was 0.952 , of which the Cronbach coefficient was 0.886 for the perceived value section with a total explained variance of perceived value of $72.719 \%$. The Cronbach coefficient was 0.916 for the reading motivation section with a total explained variance of perceived value of $71.129 \%$. The Cronbach coefficient was 0.782 for the reading comprehension section with a total explained variance of $86.973 \%$. In addition, the Cronbach coefficient for each question removed was less than 0.952. This study used the traditional practice of conducting Harman's one-way test; i.e., placing all variables into one exploratory factor analysis, and the test results showed that the KMO (Kaiser-Meyer-Olkin) value was 0.933 and the Bartlett's spherical test was significant. All variables were subjected to exploratory factor analysis, and the results of the rotated factor analysis showed that there were no cases of severe common method bias, implying that individual variables showed high discriminant validity. In summary, it can be seen that the data used in this position have good internal consistency reliability.

Next, validation factor analysis was performed. After validation factor analysis, it was found that the value of $\chi^{2} / d f$ was 2.392, which was less than 3, and the adaptation was ideal; RMSEA (root mean square error of approximation) was 0.082 , which was well adapted and the results were also well adapted; TLI (Tucker Lewis Index) was 0.937, which was greater than 0.9, and the results were well adapted. On 
the whole, the overall model adapts well.

Finally, to test the mediating effect of social reading motivation, this study drew lessons from four conditions which have been put forward by Baron and Kenny ${ }^{[10]}$ : (1) regression analysis was conducted for independent variables by dependent variables, and its regression coefficient reached a significant level; (2) regression analysis was conducted for independent variables by intermediary variables, and its regression coefficient reached a significant level; (3) regression analysis was conducted for intermediate variables by dependent variables, and its regression coefficient reached a significant level; (4) regression analysis was conducted for intermediate variables and independent variables by dependent variables, and the regression coefficient of the intermediate variable reached a significant level, while the regression coefficient of the independent variable decreases. When the regression coefficient of the independent variable still reaches a significant level, it shows that the intermediary variable plays a partial intermediary role; however, when the regression coefficient of independent variables is reduced to an insignificant level, it indicates complete mediation.

\section{Results}

\subsection{Correlation analysis between main variables}

Table 2 lists the correlation coefficients among the variables, from which it can be seen that the correlation coefficients among all the variables in this study are greater than 0.04 , indicating that there is a correlation between the variables with $P<0.01$. Among them, the correlation coefficient between the perceived value of social reading and reading ability is 0.503 , which is moderately correlated; the correlation coefficient between the perceived value of social reading and reading motivation is 0.734 , which is highly correlated. There is a significant correlation between reading motivation and reading ability, where the correlation coefficient is 0.800 , which is highly correlated. It can be seen that the correlation between the independent variable, dependent variable, and intermediary variable in the study is above moderate to a high correlation, and the data has strong research reliability.

Table 2. Correlation between perceived value of social reading, reading motivation, and reading comprehension

\begin{tabular}{|c|c|c|c|c|c|c|c|c|c|c|c|}
\hline & $\begin{array}{c}\text { Functional } \\
\text { value }\end{array}$ & $\begin{array}{c}\text { Emotional } \\
\text { value }\end{array}$ & $\begin{array}{l}\text { Social } \\
\text { value }\end{array}$ & $\begin{array}{c}\text { Social } \\
\text { interaction }\end{array}$ & $\begin{array}{c}\text { Personal } \\
\text { development }\end{array}$ & $\begin{array}{c}\text { Other people's } \\
\text { approval }\end{array}$ & $\begin{array}{c}\text { Information } \\
\text { access }\end{array}$ & $\begin{array}{l}\text { Emotional } \\
\text { expression }\end{array}$ & $\begin{array}{c}\text { Reading } \\
\text { ability }\end{array}$ & $\begin{array}{c}\text { Perceived } \\
\text { value }\end{array}$ & $\begin{array}{c}\text { Reading } \\
\text { motivation }\end{array}$ \\
\hline $\begin{array}{c}\text { Functional } \\
\text { value }\end{array}$ & 1 & & & & & & & & & & \\
\hline $\begin{array}{l}\text { Emotional } \\
\text { value }\end{array}$ & $.759 * *$ & 1 & & & & & & & & & \\
\hline $\begin{array}{l}\text { Social value } \\
\text { Social }\end{array}$ & $.481^{* *}$ & $.487^{* *}$ & 1 & & & & & & & & \\
\hline $\begin{array}{l}\text { interaction } \\
\text { Personal }\end{array}$ & $.607 * *$ & $.614^{* *}$ & $.586^{* *}$ & 1 & & & & & & & \\
\hline $\begin{array}{c}\text { development } \\
\text { Other } \\
\text { people's }\end{array}$ & $.637 * *$ & $.644^{* *}$ & $.539^{* *}$ & $.674^{* *}$ & 1 & & & & & & \\
\hline $\begin{array}{l}\text { approval } \\
\text { Information }\end{array}$ & $.535^{* *}$ & $.578^{* *}$ & $.537 * *$ & $.610^{* *}$ & $.673 * *$ & 1 & 1 & & & & \\
\hline $\begin{array}{l}\text { access } \\
\text { Emotional }\end{array}$ & $.624^{* *}$ & $.616^{* *}$ & $.575^{* *}$ & $.598^{* *}$ & $.690^{* *}$ & $.739^{* * *}$ & 1 & & & & \\
\hline $\begin{array}{l}\text { expression } \\
\text { Reading }\end{array}$ & $.399 * *$ & $.360^{* *}$ & $.426 * *$ & $.446 * *$ & $.481 * *$ & $.589 * *$ & $.553^{* *}$ & 1 & & & \\
\hline $\begin{array}{c}\text { ability } \\
\text { Perceived }\end{array}$ & $.427 * *$ & $.485^{* *}$ & $.370^{* *}$ & $.529 * *$ & $.491^{* *}$ & $.657^{* *}$ & $.588^{* *}$ & $.527 * *$ & 1 & & \\
\hline $\begin{array}{l}\text { value } \\
\text { Reading }\end{array}$ & $.873 * *$ & $.875^{* *}$ & $.791^{* *}$ & $.713^{* *}$ & $.715^{* *}$ & $.651^{* *}$ & $.715^{* *}$ & $.469^{* *}$ & $.503^{* *}$ & 1 & \\
\hline motivation & $.630^{* *}$ & $.644^{* *}$ & $.590 * *$ & $.689 * *$ & $.797^{* *}$ & $.884 * *$ & $.860^{* *}$ & $.778^{* * *}$ & $.800^{* *}$ & $.734 * *$ & 1 \\
\hline
\end{tabular}




\subsection{Structural equation modeling}

This study explores the path coefficients among individual variables using structural equation modeling and analyzes the path effects to verify the validation of $\mathrm{H} 1, \mathrm{H} 2$, and $\mathrm{H} 3$.

\subsubsection{Model construction}

According to the theoretical hypothesis of the relationship among perceived value of social reading, reading motivation, and reading ability, the following structural equation model diagram is constructed, as shown in Figure 1.

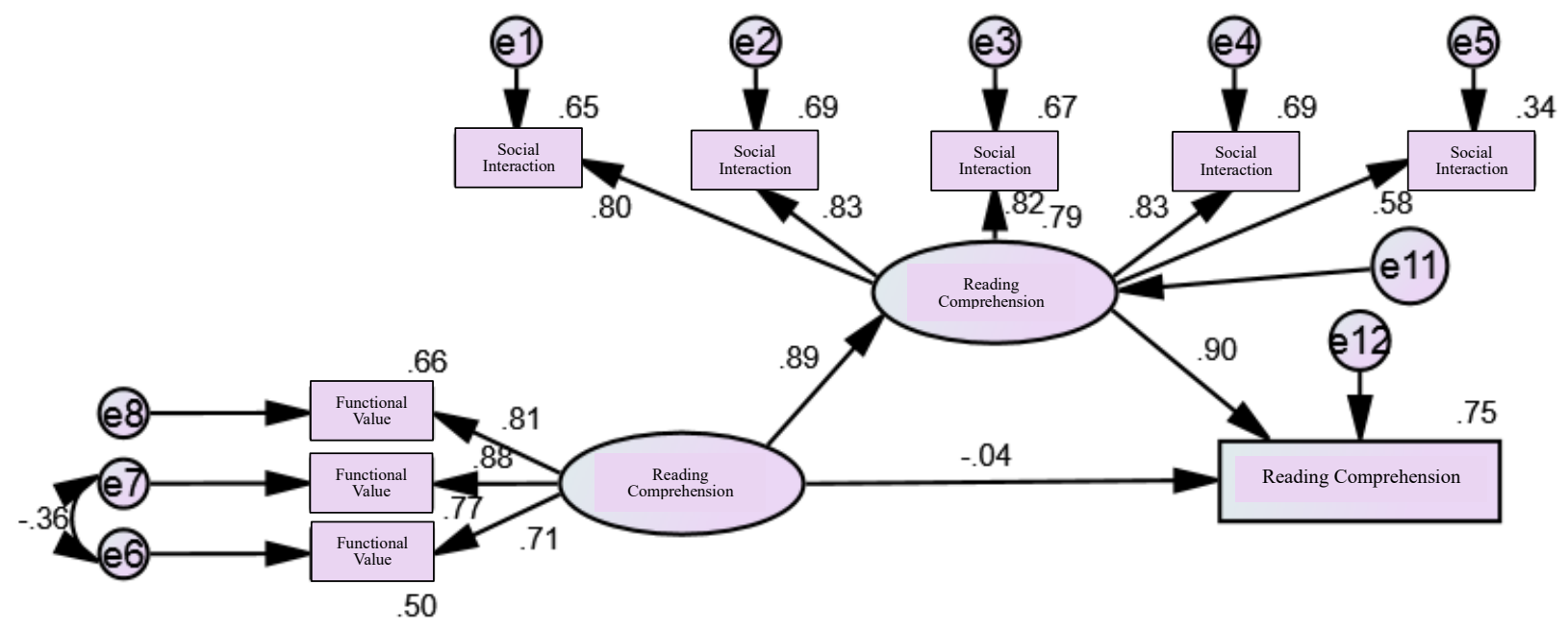

Figure 1. Structural equation model diagram

\subsubsection{Analysis of the model fit}

The perceived value of social reading, reading motivation, and reading ability were analyzed by the structural equation, and the error items were optimized and revised. The model and the situation are shown in Table 3. It can be seen that the ratio of the overall fitting index of the model is $2.854<3.000$, indicating that the model is well adapted. From the other accompanying reading indicators, all indicators meet or approach the general standard; most indicators meet the ideal standard, and the overall model fit is better, indicating that the hypothetical theoretical model fits well with the actual data.

Table 3. Analysis of the overall model fit

\begin{tabular}{cccccccccc}
\hline \multirow{2}{*}{ Fitting index } & $\begin{array}{c}\text { Chi-square } \\
\text { test }\end{array}$ & \multicolumn{3}{c}{ Moderate index } & \multicolumn{3}{c}{ Alternative index } & \multicolumn{2}{c}{ Residual analysis } \\
\hline Recommended value & X2/df $<5$ & \multicolumn{3}{c}{$>0.9$ or close to } & \multicolumn{2}{c}{$>0.9$ or close to } & $<0.08$ & $<0.08$ or close to \\
Fitted value scale & X2/df & GFI & AGFI & TLI & NFI & CFI & RMSEA & RMR \\
Fitting index & 2.854 & 0.988 & 0.974 & 0.947 & 0.945 & 0.963 & 0.094 & 0.127 \\
\hline
\end{tabular}

\subsubsection{Analysis of the model path}

In this study, the data collected were subjected to structural equation modeling using Amos 23.0. The running results were collated and analyzed to obtain the standard path coefficients for the model as shown 


\section{in Table 4.}

Table 4. Table of standard coefficient

\begin{tabular}{ccccc}
\hline Path relationships & $\begin{array}{c}\text { Standard path } \\
\text { coefficient }\end{array}$ & Standard error & Critical value & Significance $P$ \\
\hline Reading motivation $\leftarrow$ Perceived value & 0.89 & 0.104 & 9.282 & $* * *$ \\
Reading comprehension $\leftarrow$ Reading motivation & 0.90 & 0.180 & 6.057 & -0.098 \\
Reading ability $\leftarrow$ Perceived value & -0.04 & 0.190 & $* * *$ \\
\hline
\end{tabular}

Note: $* * *$ indicates that $P$ is less than 0.001 and is highly significant (the level of significance is 0.05 ).

As shown in Table 4, perceived value has a significant positive effect on reading motivation with an effect coefficient of 0.89 . Reading motivation has a significant positive effect on reading comprehension with an effect coefficient of 0.9. Perceived value has a significant negative effect on reading ability with an effect coefficient of -0.04 .

\subsection{Analysis on the mediating effect of reading motivation}

After completing the correlation analysis, the specific mechanism among the variables and the mediating effect of reading motivation were explored to verify the hypotheses. By using the four conditions proposed by Baron et al. for reference, four models were made through regression analysis, as shown in Table 5. It can be seen from Table 5 that the perceived value and reading motivation have a highly significant positive impact on reading ability. Therefore, reading motivation plays a significant mediating role.

Table 5. Summary of the analysis on the mediating effect of reading motivation in perceived value on reading comprehension

\begin{tabular}{|c|c|c|c|c|c|c|c|c|}
\hline \multirow{4}{*}{ Variables } & \multicolumn{8}{|c|}{$\begin{array}{l}\text { Regression model } \\
\text { Dependent variable }\end{array}$} \\
\hline & \multirow{2}{*}{\multicolumn{2}{|c|}{$\begin{array}{l}\text { Reading motivation } \\
\text { Model } 1\end{array}$}} & \multicolumn{6}{|c|}{ Reading ability } \\
\hline & & & \multicolumn{2}{|c|}{ Model 2} & \multicolumn{2}{|c|}{ Mode 3} & \multicolumn{2}{|c|}{ Model 4} \\
\hline & $\beta$ & $t$ & $\beta$ & $t$ & $\beta$ & $t$ & $\beta$ & $t$ \\
\hline Perceived value & 0.787 & $16 .^{188^{* * * *}}$ & 0.698 & $8 .^{719 * * *}$ & - & - & $-0.252^{* * * *}$ & -3.144 \\
\hline Reading motivation & - & - & - & - & $1 .^{034 * * *}$ & 19.946 & $1.207 * * * *$ & 16.115 \\
\hline F-value & \multicolumn{2}{|c|}{$262 . .^{056 * * *}$} & \multicolumn{2}{|c|}{76.015} & \multicolumn{2}{|c|}{397.831} & \multicolumn{2}{|c|}{211.750} \\
\hline R2 & \multicolumn{2}{|c|}{0.54} & \multicolumn{2}{|c|}{.253} & \multicolumn{2}{|c|}{640} & \multicolumn{2}{|c|}{.655} \\
\hline$\triangle \mathrm{R} 2$ & \multicolumn{2}{|c|}{0.54} & \multicolumn{2}{|c|}{.253} & \multicolumn{2}{|c|}{.640} & \multicolumn{2}{|c|}{.655} \\
\hline Hypothesis testing results & \multicolumn{2}{|c|}{ Established } & \multicolumn{2}{|c|}{ Established } & \multicolumn{2}{|c|}{ Established } & \multicolumn{2}{|c|}{ Established } \\
\hline
\end{tabular}

\section{Discussion and suggestions}

The cultivation of teenagers' reading ability is of great significance to their learning and future work. In the context of social reading, there is a significant correlation between teenagers' perceived value of social reading and reading ability ${ }^{[11]}$. Existing studies tended to focus on the role of perceived value in relation to the marketization of social reading software, while neglecting that perceived value can also affect teenagers' reading motivation. Regardless of the mediating effect of reading motivation, this study systematically investigated the influence of the perceived value of social reading on teenagers' reading ability in the whole chain from content production to teenagers' use. 


\subsection{Result and discussion}

The first is the mediating role of reading motivation. This study shows that the perceived value of social reading affects teenagers' reading ability through the intermediary of reading motivation, which is consistent with the hypothesis. Teenagers' perceived value of socialization would trigger reading motivation. First, the functional value of social reading would trigger teenagers' motivation to obtain information. It is believed that social reading platforms can provide more complete information and meet the needs of teenagers in obtaining information. Second, the emotional value of social reading would trigger teenagers' reading motivation through social interaction and emotional expression. Not only would they achieve self-satisfaction through social reading platforms, but also relaxation through communication and interaction with their peers on those platforms. Teenagers may feel that social reading always has a good topic or content to share, and through these topics or contents, they are able to interact with other students. At the same time, it enables teenagers to feel contentment and happiness during their spare time. Third, the social value of social reading would trigger teenagers' reading motivation, such as personal development and other people's identity. Through the perception of social value, teenagers may feel the improvement of their ability, academic progress, and personal accomplishment. In addition, they may gain more peer recognition by sharing common topics with other people.

\subsection{Enlightenment of the mediating role of reading motivation}

This study proves that reading motivation plays an important role in promoting teenagers' reading proficiency by perceived value. For government departments, while promoting teenagers' reading ability, they should also strengthen the publicity of reading resources, so as to promote teenagers' appreciation of the value of reading resources. In other words, the more an individual knows about the background of the reading resources, the greater the possibility of using those reading resources. This would stimulate teenagers' reading motivation along with their interest and enthusiasm for reading. It can be issued in the process of in-depth understanding and analysis of the recommended teaching and reading resources, so that on the one hand, more high-quality resources would flow into the campus, classrooms, and eventually the hands of teenagers; on the other hand, it can also enhance the perceived value of reading resources among teenagers. Schools should encourage teachers and students to carry out social reading and promote good social reading platforms. Using a reading platform in a certain local area does not only improve the effectiveness of content-sharing with each other, but also enhance teenagers' feelings for social reading platforms, thus further stimulating their interest in reading. For teenagers, the perceived value of social reading can improve their universality of reading from another aspects, not only in terms of directly understanding the knowledge content of reading resources, but also the background of those reading resources, so that their reading ability can be comprehensively improved.

\section{Funding}

This study was supported by the Special Support Project for Humanities and Social Sciences of Guangzhou University of Chinese Medicine (2021SKZX04).

\section{Disclosure statement}

The authors declare that there is no conflict of interest.

\section{References}

[1] Gu X, Feng Y, Hu S, 2015, Beyond Fragmented Learning: Semantic Graphing and Deep Learning. 
China Educational Technology, (03): 39-48.

[2] Li W, 2017, A Study on the Influence of Perceived Value on User Satisfaction and Loyalty of E-Book Reading Clients. Journal of Library Science in China, 43(06): 35-49.

[3] Xuan H, Dai T, Nin Q, et al., 2018, On the Influence of APP Marketing on Group Purchasing Behavior. Journal of Commercial Economics, (03): 103-106.

[4] Zheng J, Tang S, 2017, An Empirical Study on Factors Influencing User Satisfaction of Teenagers' Online Popular Science Channel Based on ACSI Model - Taking "Science Principle Learning" Channel as an Example. Studies on Science Popularization, 12(04): 43-52, 106.

[5] Gu H, Liu J, Xia T, 2017, Influence of Family Socioeconomic on Primary School Students' Reading Autonomy: Mediating Role of Parental Encouragement and Reading Motivation. Acta Psychologica Sinica, 49(08): 1063-1071.

[6] Liu X, Zhang L, 2019, Study on the Influence of Social Reading Platform Characteristics and Perceived Value on Users' Willingness to Continue Using. New Century Library, (12): 53-56.

[7] Li J, 2017, A Study on the Effect of Social Reading on Reading Ability of Chinese Teenagers. China Publishing, (05): 21-25.

[8] Saiyidi MR, Hadrian GD, 2021, Data Analysis with SPSS for Survey-based Research, 15-142.

[9] $\mathrm{Hu} \mathrm{D}, \mathrm{Zhu}$ Z, 2020, Questionnaire Reliability Validity Test Based on SPSS and AMOS: A Study on the Relationship between Mathematical Anxiety, Mathematical Attitude and Mathematical Efficacy as an Example. Educational Measurement and Evaluation, (11): 3-7, 28.

[10] Baron RM, Kenny DA, 1986, The Moderator-Mediator Variable Distinction in Social Psychological Research: Conceptual, Strategic, and Statistical Considerations. Journal of Personality and Social Psychology, 51(6): 1173-1182.

[11] Chen M, 2016, Research on the Relationship between College Students' Socialized Reading Motivation, Behavior and Social Capital. Shanghai Jiaotong University. 